BERICHTE UBER DIE VERHANDLUNGEN DER SÄCHSISCHEN AKADEMIE DER WISSENSCHAFTEN ZU LEIPZIG

Philologisch.historische Klasse

Band 98 . Heft 3

JAKUB WJACSŁAWK

\title{
SERBSKA BIBLIOGRAFIJA
}

2. rozmnoženy a wuporjedźany nakład

JACOB JATZWAUK

\section{SORBISGHE (WENDISGHE) BIBLIOGRAPHIE}

2. erweiterte und verbesserte Auflage

1952

AKA DEM IE - VERLA G - B E RL I N 
Vorgelegt in der Sitzung vom 20. März 1950

Manuskript eingeliefert am 11. Mai 1950

Druckfertig erklärt am 23. November 1951

Erschienen im Akademie-Verlag GmbH., Berlin NW 7, Schiffbauerdamm 19

Lizenz-Nr. $202 \cdot 100 / 81 / 50$

Gesamtherstellung: Druckhaus ${ }_{n}$ Maxim Gorki“, Altenburg/Thür.

Bestell- und Verlagsnummer 2026/98/3

Preis: DM 16,-

Printed in Germany 
MOJEMU LUBEMU SYNEJ

wěnowane

\section{MEINEM LIEBEN SOHN}

zugeeignet 
